\title{
Study on the Relationship Between Sedimentary Characteristics of Shallow Soil Layer and Shear Wave Velocity in Qingdao
}

\author{
Li Tiefei, Lu Hongshan, Chen Xueliang, Li Zongchao \\ Institute of Geophysics, China Earthquake Administration, Beijing, China
}

2fen222@163.com

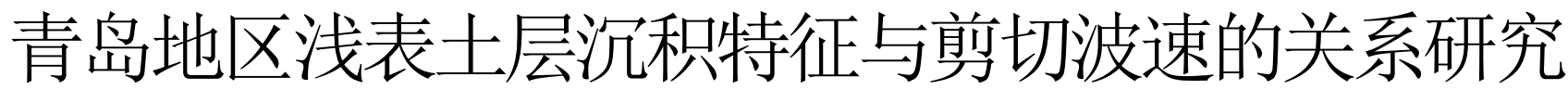

李铁飞, 吕红山, 陈学良, 李宗超

中国地震局地球物理研究所, 北京, 100081 , 中国

2fen222@163.com

\begin{abstract}
Based on the histogram and shear wave velocity data of 449 boreholes in the Jiaozhou Bay area of Qingdao, the empirical relationship between soil depth and shear wave velocity is calculated. The empirical relationship and sedimentary environment characteristics are analyzed. In connection with the soil layer, which has a long transport distance and a relatively small particle size, the shear wave velocity is relatively low. The empirical relationship between depth and shear wave velocity in the depth of $20 \mathrm{~m}$ depth of the soil layer with obvious sedimentary features in the Jiaozhou Bay area of Qingdao is given. For the soil layer without obvious sedimentary features, the sedimentary features of the remaining strata of the borehole are used for classification, which improves the fitting degree of the empirical relationship and reduces the error, thus giving a method to estimat shear wave velocity of borehole using bore histogram with obvious sedimentary characteristics.
\end{abstract}

Keywords-Sedimentary Characteristics, Shear Wave Velocity, Statistical Analysis

摘要一以青岛环胶州湾地区 449 个小区划钻孔的柱状图和 剪切波速数据为基础, 统计了土层埋深与剪切波速之间的经验 关系特征, 分析了该经验关系与沉积环境特征的联系, 认为搬 运距离较长、颗粒相对较小的土层, 其剪切波速相对较小。给 出了青岛环胶州湾地区沉积特征明显土层在 $20 \mathrm{~m}$ 深度范围内 深度与剪切波速的经验关系。对于沉积特征不明显的土层, 使 用其所在钻孔的其余地层的沉积特征进行分类, 提高了其经验
关系拟合度, 减小了误差, 从而给出了一种根据具有明显沉积 特征土层测井数据估算未测波速钻孔的等效剪切波速的方法。

关键词一沉积特征, 剪切波速, 统计分析

\section{I 引言}

沉积环境和沉积作用的各种特点, 会在沉积产物中留 下某些记录, 对土层而言其主要表现为土层颗粒的组分、 几何形态、结构等方面的差异 ${ }^{[1]}$ 。例如, 水动力环境会影 响沉积物颗粒的特征, 土层颗粒的特征会影响它们之间 的孔隙大小、配位数、摩擦力等特征, 从而进一步影响土 层的剪切波速等物理性质。沉积土层不同的物理性质以 及分层结构共同构成了地下的速度结构, 从而对地震动 产生一定程度的影响。尤其对于局部地质条件, 如地表几 十米内的土壤沉积层, 这种影响十分显著。

局部地质条件在地震工程学中一般称为场地条件, 国 内外的震害经验一致表明, 场地条件是引起地表震害和 地震动局部变化的重要因素, 而场地土壤对震害的影响 在场地条件中占首要地位 ${ }^{[2]}{ }^{[3]}$, 其中, 剪切波速及其在空 间上的速度结构是对地面运动影响最大的因素。因此, 研 究土层颗粒特征与土层剪切波速的关系, 有助于认识、验 证以致提前估计不同地区土体的物理力学特性以及它们 对地震动的影响。

青岛地区的地震灾害主要受到跨华北地震区的长江 下游一南黄海地震带和郯庐地震带影响, 而郯庐地震带 目前仍处在这个地震活跃期的后期。青岛市经济比较发 达, 人口密度较大, 历史上不同程度地遭受 $V$ 度以上地震 
影响的共有 6 次。因此, 本文将对青岛地区浅表土层沉积 特征与剪切波速的关系进行分析。

建立高精度速度结构模型是研究场地效应的有效方 法, 该方法需要以大量的地球物理勘探资料为基础。然而, 地球物理勘探的成本较高, 且对于人口、建筑密集的地区, 地球物理勘探, 尤其是钻孔钻探具有很大的难度。本文中 尝试建立的使用特定土层的颗粒特征估计其等效剪切波 速的方法, 使未进行波速测井的钻孔数据可以被利用于 场地模型的构建, 增加场地速度结构模型的准确性; 同时 将受沉积环境影响的土层颗粒特征与剪切波速建立一定 的联系, 是将第四系沉积理论与地震工程学相结合, 使用 地质资料完善工程场地物理性质资料的尝试。

\section{II. 青岛环胶州湾地区各类土层剪切波速与埋 深关系的统计分析}

青岛地区的地震灾害主要受到跨华北地震区的长江 下游一南黄海地震带和郯庐地震带影响, 其中, 欵庐地震 带是我国东部规模最大的地震带, 总体走向为 NNE 向, 长江下游一南黄海地震带的地震主要受长江下游苏北拗 陷内的北东一北北东向断裂和南黄海内部近东西向的北 部拗陷和南部拗陷边界断裂及内部一些较大断裂的控制。 区域范围内, 沂沭断裂带是最主要的地震构造。沂沭断裂 带是整个㸚庐断裂带上出露最好、规模最大、新活动最强 烈的地区; 在大地构造单元上, 青岛地区属苏北一胶南断 块, 新构造运动以长期的、间歇性的隆升运动为特征。

青岛地区的第四系十分发育, 主要分布在各条河流的 下游的阶地、洪冲积平原以及山麓沟谷、山间凹地等低凹 开阔地段, 属晚更新世晚期至全新世时期的产物。晚更新 世晚期均为陆相沉积物; 全新世时期既有陆相也有海相 沉积物。胶州湾南连黄海, 周围河流主要受地形、地貌及
人工影响控制, 其水文动态受季节性变化较大, 为季节性 雨源型, 多为独立入海的山溪性小河, 主要有李村河、白 沙河、墨水河、大沽河、洋河等。河流的冲积对其场区第 四系地层的沉积起了十分重要的作用。

本文对青岛地区 449 个钻孔柱状图及波速测试结果 进行了整理, 得到了所有土层, 包括黏土层、角砾层、砾 砂层、粗砂层、中砂层、细砂层、淤泥层以及淤泥质粉质 黏土层等多类地层的的的深度、层厚度、层平均波速以及 钻孔柱状图对该土层的描述中的颗粒大小等土层颗粒特 征。

为了分析青岛环胶州湾地区浅层各类土层的剪切波 速与埋深的关系特征, 文中采用常用的线性拟合方法[4][5] 统计了不同类型土层的剪切波速与埋深的关系。拟合公 式为 $\mathrm{Y}=\mathrm{a}+\mathrm{bX}$ 。拟合结果见表 1 。由拟合结果可见, 将各 类土层分别进行拟合，除黏土、粉质黏土层和含有淤泥的 土层以外, 其余土层的校正决定系数均比将所有土层共 同拟合时更接近于 1 , 平均残差平方更小, 表明研究区域 中的角砾、粗砾砂、砾砂、粗砂、中粗砂、中砂、中细砂、 粉细砂层的剪切波速与埋深的相关性较高。该类土层有 一个共同特点：其颗粒特征或者说沉积特征十分明显。

对于含有淤泥的地层而言, 其校正决定系数很低的同 时评价残差平方也很低, 这表明含淤泥地层的剪切波速 余埋深的关系不大, 但是由于含有相似的成分, 其平均值 趋于一个定值, 从实际数据来看, 该类土层的埋深较浅。 因此, 对于含淤泥类土层, 可以直接使用平均值来描述研 究区域内同类土层在极浅层 ( $10 \mathrm{~m}$ 以内) 的剪切波速。

对于粉质黏土和黏土层, 其拟合度较差, 离散性较大, 可能是由于柱状图中对黏土的描述无法体现出其具体的 颗粒特征, 难以对其作出进一步的分类。

表 1 环胶州湾地区土层深度-波速拟合结果

\begin{tabular}{|c|c|c|c|c|c|}
\hline \multirow{2}{*}{ 沉积层类别 } & \multicolumn{2}{|c|}{ 回归参数值 } & \multirow{2}{*}{ Adj. R-Square } & \multirow{2}{*}{ Mean Square } & \multirow{2}{*}{ 样本数 } \\
\hline & $a$ & $\mathrm{~b}$ & & & \\
\hline 所有土层 & 131.37479 & 6.89542 & 0.48417 & 1945.613 & 1036 \\
\hline 角砾 & 244.40497 & 2.70269 & 0.8359 & 87.0597 & 5 \\
\hline 粗砾砂 & 156.47091 & 6.4392 & 0.50128 & 1667.362 & 215 \\
\hline 砾砂 & 122.3286 & 8.77539 & 0.8481 & 1492.439 & 13 \\
\hline 粗砂 & 156.55398 & 4.05098 & 0.60448 & 379.6048 & 89 \\
\hline 中粗砂 & 122.82276 & 8.39028 & 0.54464 & 777.0898 & 46 \\
\hline 中砂 & 130.85523 & 6.71376 & 0.62688 & 669.0066 & 18 \\
\hline 中细砂 & 128.81617 & 6.10726 & 0.62886 & 602.0778 & 10 \\
\hline 粉细砂 & 140.83511 & 3.37918 & 0.52785 & 136.5815 & 13 \\
\hline
\end{tabular}




\begin{tabular}{cccccc}
\hline 淤泥 & 124.08276 & 2.9953 & 0.09773 & 390.7064 & 23 \\
\hline 淤泥质细砂 & 136.42487 & 4.47607 & 0.24998 & 749.7357 & 14 \\
\hline 淤泥质粉细砂 & 129.34295 & 4.45135 & 0.2063 & 322.5164 & 18 \\
\hline 淤泥质粉质粘土 & 135.22178 & 0.75499 & $-2.52 \mathrm{E}-04$ & 270.2525 & 58 \\
\hline 淤泥质土 & 137.57102 & 0.82781 & 0.03192 & 767.2318 & 146 \\
\hline 粘土、粉质粘土 & 166.90294 & 4.38437 & 0.18913 & 2464.801 & 368 \\
\hline
\end{tabular}

图 1 为拟合度较高的土层的线性拟合结果, 由图可 见, 在青岛环胶州湾浅层 $20 \mathrm{~m}$ 范围内, 颗粒特征明显的 角砾层、粗砾砂层、砾砂层、砾砂、中粗砂、中砂、中细 砂、粉细砂层的剪切波速呈现出由高到低的趋势, 土层颗 粒大小与剪切波速呈现出明显的相关性。这几类土层在 研究范围内的剪切波速与埋深的相关性较高, 表 1 中的 拟合结果在缺乏波速数据的模型构建中可以作为经验公 式使用。

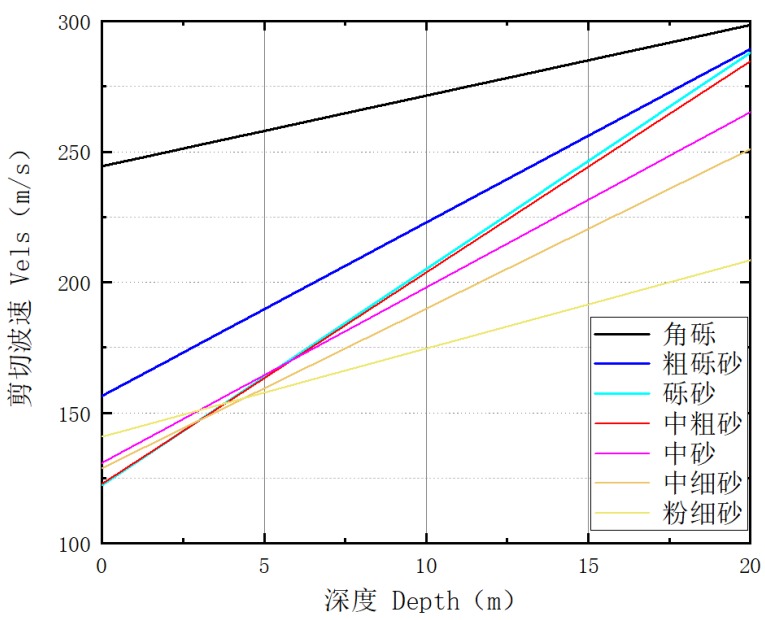

图 1 不同种类土层的线性深度-波速拟合结果对比

拟合结果表明, 青岛环胶州湾地区具有明显颗粒特征 的土层的剪切波速与埋深的相关性较高, 其主要原因是 具有相同颗粒特征的土层具有相似的沉积物源且形成于 相似的沉积环境中, 并分布于环胶州湾地区地质条件相 似、地理位置相近的区域内, 具有相似的物理性质。对于 黏土层和粉质黏土层, 难以从柱状图的描述中获得明显 的颗粒特征并对其进行进一步的分类，这是由黏土本身 颗粒较小的特点决定的。

同时, 对于颗粒特征明显的土层, 其剪切波速与颗粒 大小有明显的正相关关系, 颗粒较大的角砾层剪切波速 最高、其余粗砾砂层、砾砂、中粗砂、中砂、中细砂的颗 粒大小与剪切波速大小排列基本一致，颗粒最小的粉细 砂剪切波速最低。因此, 本文将进一步分析青岛环胶州湾 地区图层剪切波速与其颗粒特征、沉积特征之间的关系。

\section{III. 青岛环胶州湾地区沉积土层的沉积特征 与剪切波速的关系的讨论}

为了研究青岛环胶州湾地区土层颗粒特征与剪切波 速的关系, 将搜集整理的钻孔数据按照沉积物的颗粒大 小进行重新分类: 将角砾层和粗砾砂归为颗粒大一类; 将 砾砂、中粗砂、中砂归为颗粒中一类, 将中细砂、粉细砂 归为颗粒小一类将重新分类后的数据再次进行拟合。结 果见表 2 及图 2。由拟合结果可见, 剪切波速与沉积物颗 粒大小有明显的关系, 沉积物颗粒越大, 则其剪切波速越 高。由于青岛环胶州湾地区浅层土层主要为河流沉积和 海相沉积, 可以推测, 土层的剪切波速与其形成时所处的 水动力沉积环境有一定的关系。同时, 这三种分类的矫正 决定系数都比全部土层一起拟合更高, 平均残差更低, 因 此该拟合结果有一定的参考价值。

沉积物颗粒大小与水流的搬运能力有关, 水流量越大, 流速越快则其能够搬运的沉积物颗粒越大; 大量的现代 河流砾石的调查支持了向下游方向砾石粒径减少的认识 [6]。因此, 青岛环胶州湾地区浅层土层的剪切波速与其形 成时所处的水动力环境有关。具体表现为, 颗粒较小的沉 积物在水流中搬运的距离较长, 所形成的沉积层波速较 低; 较大的沉积物颗粒在水流中搬运的距离较短, 形成的 沉积层波速较高。

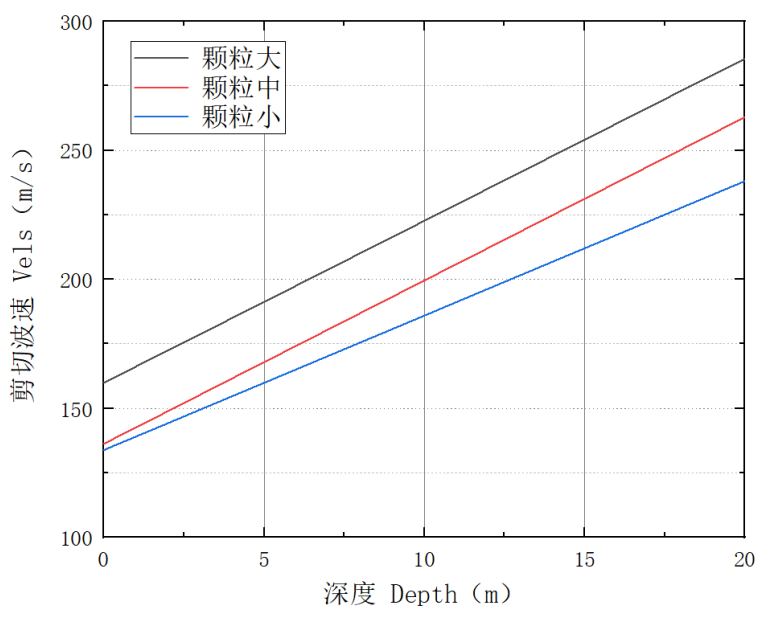

图 2 颗粒大小不同的土层的深度-波速线性拟合结果 
表 2 颗粒大小不同的土层的深度-波速线性拟合结果

\begin{tabular}{cccccccc}
\hline \multirow{2}{*}{ 沉积层类别 } & \multicolumn{2}{c}{ 回归参数值 } & & \multirow{2}{*}{ Adj. R-Square } & Mean Square & 样本数 \\
\cline { 2 - 3 } & $\mathrm{a}$ & $\mathrm{b}$ & & & & \\
\hline 颗粒大 & 159.85723 & 6.27841 & & 0.48902 & 1680.292 & 220 \\
\hline 颗粒中 & 136.25735 & 6.23699 & & 0.64847 & 874.4215 & 166 \\
\hline 颗粒小 & 133.81735 & 5.21186 & & 0.63704 & 343.257 & 23 \\
\hline
\end{tabular}

这一方面是由于不同颗粒大小和颗粒级配等沉积特 征对沉积土层的孔隙率、配位数、含水率、颗粒间摩擦力 等特征的影响, 另一方面是由于不同大小的沉积物颗粒 由于沉积物源的不同, 其本身的弹性模量不同。较小的颗 粒可能来自风化程度较高的软弱岩石, 其本身的弹性模 量较低; 而较大的颗粒可能来自风化程度较低的坚硬岩 石，其本身的弹性模量较高。

总体而言, 本文认为, 青岛环胶州湾地区, 对于沉积 物颗粒特征明显的土层, 与其碎屑物源供给区距离越远, 则其剪切波速越低。此外, 沉积土层的波速还可能与沉积 过程中的化学作用、生物作用等其他因素有关, 仍有待进 一步的研究。

\section{IV. 由颗粒特征明显的土层的数据估计青岛环 胶州湾地区钻孔的等效剪切波速}

对于一些地质资料或者工程资料中的钻孔, 通常其柱 状图中只有土层的分层以及性质的描述，而没有波速测 试的资料。利用前文分析得到的青岛胶州湾地区颗粒特 征明显的土层的波速-深度经验公式，可以给出一种由这 类土层估计场地等效波速的方法, 从而利用只有地层分 层及性质的钻孔资料, 在地震地面运动分析时作为有波 速测井的钻孔资料的补充。

然而, 对于占了总体土层数据点数数约三分之一的粘 土层、粉质粘土层（如果计算厚度其占比更大）, 其拟合 结果较差, 无法作为经验公式对未知场点进行剪切波的 估计。为了考虑离散性较大的土层的影响, 本文中使用钻
孔场地的 “沉积特征” 对黏土层、粉质黏土层进行进一步 的分类，以提高其经验关系的拟合优度。

假设黏土层、粉质黏土层的沉积特征与其所在钻孔的 其它土层的颗粒特征有一定的关系, 将黏土层、粉质黏土 层按照其所属的钻孔土层的颗粒特征进行分类。本文中 将青岛环胶州湾地区的黏土层、粉质黏土层按照其所处 钻孔土层的颗粒大小, 分为颗粒大、颗粒中、颗粒小、无 法区分四类。即：同钻孔中含角砾、粗砾砂较多则为颗粒 大; 同钻孔中含砾砂、中粗砂、中砂则为颗粒中; 同钻孔 中含中细砂、粉细砂则为颗粒小, 全部不含则为无法分类。

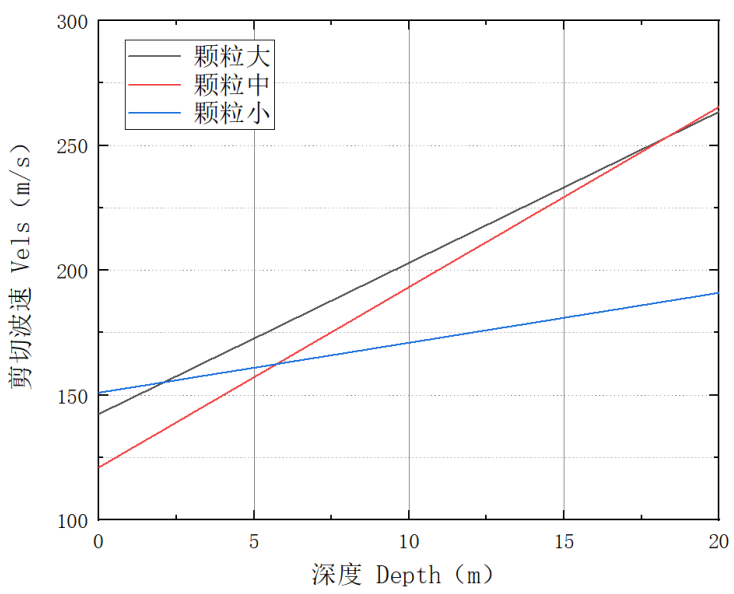

图 3 沉积特征不同的黏土、粉质黏土层的深度-波速 线性拟合结果

表 3 沉积特征不同的黏土、粉质黏土层的深度-波速线性拟合结果

\begin{tabular}{|c|c|c|c|c|c|}
\hline \multirow{2}{*}{ 沉积层类别 } & \multicolumn{2}{|c|}{ 回归参数值 } & \multirow{2}{*}{ Adj. R-Square } & \multirow{2}{*}{ Mean Square } & \multirow{2}{*}{ 样本数 } \\
\hline & a & $b$ & & & \\
\hline 颗粒大 & 142.4381 & 5.75036 & 0.38602 & 1864.479 & 195 \\
\hline 颗粒中 & 121.0599 & 7.51817 & 0.50618 & 2019.412 & 121 \\
\hline 颗粒小 & 170.9689 & 1.70026 & 0.03126 & 1028.241 & 38 \\
\hline 全部不含 & 194.2734 & 6.00075 & 0.08123 & 2548.975 & 52 \\
\hline
\end{tabular}


分别对这四个分类其进行深度-波速关系的拟合。拟 合结果见图 3 和表 3 , 由表可见, 按照假设分类后黏土 层、粉质黏土层的拟合度明显提高, 而无法分类的剩余 数据, 离散性极大。首先, 这表明本假设在一定程度上 反应了研究区域内黏土层、粉质黏土层的剪切波速特 性, 该分类较为合理。同时, 所在钻孔的 “沉积特征” 为颗粒大的黏土层、粉质黏土层, 其剪切波速也较高, 这表明黏土层的剪切波速也受到沉积特征因素的影响， 且与颗粒特征明显的土层具有相似的规律。另一方面, 这可能是由于黏土层混有少量的上覆、下覆地层的颗 粒, 在柱状图描述中没有体现。

表 4 由颗粒特征明显的土层估计钻孔等效波速

\begin{tabular}{|c|c|c|c|c|}
\hline $\begin{array}{l}\text { 钻孔 } \\
\text { 编号 }\end{array}$ & $\begin{array}{c}\text { 实际等效波速 } \\
(\mathrm{m} / \mathrm{s})\end{array}$ & $\begin{array}{c}\text { 估计等效 } \\
\text { 波速 } \\
(\mathrm{m} / \mathrm{s})\end{array}$ & $\begin{array}{c}\text { 各土层平 } \\
\text { 均误差 } \\
(\mathrm{m} / \mathrm{s})\end{array}$ & $\begin{array}{l}\text { 估计 } \\
\text { 误差 } \\
(\mathrm{m} / \mathrm{s})\end{array}$ \\
\hline 0117 & 204.4 & 211.4 & 30.1 & 7.1 \\
\hline 0018 & 189.3 & 224.4 & 36.2 & 35.0 \\
\hline 0281 & 254.9 & 219.6 & 39.1 & 35.2 \\
\hline 0282 & 227.8 & 209.8 & 21.7 & 18.1 \\
\hline 0287 & 254.0 & 221.2 & 74.4 & 32.8 \\
\hline 0328 & 212.0 & 211.0 & 20.2 & 1.0 \\
\hline 2013 & 179.9 & 214.1 & 49.9 & 34.2 \\
\hline 2015 & 210.7 & 232.7 & 22.2 & 22.0 \\
\hline 2017 & 214.7 & 238.2 & 41.9 & 23.6 \\
\hline 2019 & 238.6 & 273.4 & 49.8 & 34.9 \\
\hline 2020 & 295.3 & 259.0 & 56.7 & 36.2 \\
\hline 2030 & 233.2 & 238.6 & 20.9 & 5.4 \\
\hline 2033 & 222.1 & 225.0 & 21.9 & 2.9 \\
\hline 2034 & 193.7 & 203.9 & 18.1 & 10.2 \\
\hline 2036 & 218.6 & 212.0 & 15.1 & 6.6 \\
\hline 2039 & 260.7 & 238.4 & 32.9 & 22.3 \\
\hline Y36 & 183.4 & 223.7 & 51.9 & 40.3 \\
\hline Y90 & 193.8 & 225.7 & 36.4 & 31.9 \\
\hline Y93 & 205.4 & 239.8 & 32.6 & 34.4 \\
\hline Y97 & 187.2 & 225.3 & 42.5 & 38.1 \\
\hline Y143 & 262.3 & 220.1 & 43.5 & 42.1 \\
\hline D20 & 233.6 & 217.5 & 67.8 & 16.2 \\
\hline 0087 & 197.5 & 175.9 & 30.0 & 21.5 \\
\hline 0092 & 163.6 & 194.2 & 28.5 & 30.6 \\
\hline 0093 & 211.8 & 199.2 & 12.2 & 12.6 \\
\hline
\end{tabular}

\begin{tabular}{ccccc}
\hline 0096 & 180.0 & 195.4 & 17.3 & 15.4 \\
\hline 0097 & 173.9 & 193.9 & 32.4 & 20.0 \\
\hline 0099 & 183.5 & 193.3 & 35.4 & 9.8 \\
\hline 0102 & 155.6 & 194.6 & 58.3 & 39.0 \\
\hline 0104 & 167.3 & 197.0 & 40.3 & 29.7 \\
\hline \multicolumn{7}{c}{ 总平均误差(m/s) } & 36.0 & 23.6 \\
\hline
\end{tabular}

由上述拟合结果, 即可得到修正后的黏土层、粉质黏 土层的估计波速值。至此, 我们得到了除了表 3 中“全部 不含”分类的 50 个左右数据点以外的全部土层的深度-波 速经验公式, 从而对目标钻孔所有土层的剪切波速进行 估计, 即可进一步对目标钻孔的等效波速进行估计。为了 验证这种估计方法的准确性, 按照上述方法对青岛环胶 州湾地区的 30 个钻孔的等效剪切波速进行估计, 其结果 见表 4。由该结果可见, 本方法对所使用的钻孔数据进行 剪切波速估计时, 对于同一个钻孔的各个土层而言, 其估 计误差相对较大, 为 $36 \mathrm{~m} / \mathrm{s}$, 离散性也相对较大, 最大值 超过 $70 \mathrm{~m} / \mathrm{s}$, 实际使用时应该慎重。对于各钻孔的整体等 效剪切波速而言, 其估计误差相对较小, 为 $23.6 \mathrm{~m} / \mathrm{s}$, 离 散性也较小, 可以用于场地类型的判定等工程应用或者 场地模型参数的估计等科学计算。

\section{v. 结论与讨论}

青岛胶州湾地区, 角砾、砾砂、砾砂、中粗砂、中砂、 中细砂、粉细砂等颗粒特征明显的地层, 其剪切波速-深 度拟合结果的相关性较好, 均方差较小, 可以通过经验关 系对这类土层的剪切波速进行估计。同时, 研究区域土层 的剪切波速与沉积特征有关, 具体表现为, 颗粒较小的沉 积物在水流中搬运的距离较长, 所形成的沉积层波速较 低; 较大的沉积物颗粒在水流中搬运的距离较短, 形成的 沉积层波速较高。

文中给出了一种使用沉积特征明显的钻孔柱状图估 计钻孔等效剪切波速的方法, 可用于青岛环胶州湾地区 未测波速钻孔的剪切波速估计。对于本文研究区域内的 等效剪切波速, 平均误差为 $23.6 \mathrm{~m} / \mathrm{s}$ 。然而该方法有一定 的局限性: 首先, 要以一定数量的带有波速测试结果的钻 孔资料为基础, 使沉积特征明显的土层的样本达到一定 的数量; 其次, 估计目标钻孔也必须具备多层有相类似积 特征的土层。

研究土层的沉积特征、颗粒特征与场地条件中的关键 因素剪切波速的关系, 是使用地质资料对地球物理模型 参数进行完善的一种尝试。在地震地面运动的研究中, 可 以利用丰富的地质资料对地球物理勘探资料较少的地区, 或者难以开展地球物理勘探工作的地区进行一定程度的 补充, 具有一定的应用价值。 


\section{致谢}

本项目受到国家自然科学基金青年科学基金项目 “水 动力环境与土层剪切波速的关系研究 - - 以玉溪盆地 为例” (51808513) 的资助。

\section{参考文献}

[1] 王良忱. 1996. 沉积环境和沉积相[M]. 石油工业出版社.

[2] 胡聿贤. 2006. 地震工程学[M]. 第二版. 北京:地震出版社.

[3] 薄景山, 李秀领, 李山有. 2003. 场地条件对地震动影响研究的若 干进展[J]. 世界地震工程, 19(2): 11-15.

[4] 刘红帅,郑桐薄景山, 刘德东, 齐文浩. 2010. 粘性土剪切波速不确 定性的统计分析 [J]. 世界地震工程, 26(增) : 99-103.

[5] 邱志刚, 薄景山,罗奇峰. 2011. 土壤剪切波速与埋深关系的统计分 析[J]. 世界地震工程, 27(3): 81-88,

[6] 胡修棉, 2017, 物源分析的一个误区: 砂粒在河流搬运过程中的变 化. 古地理学报, Vol.19(1):175-184. 